\title{
PERENCANAAN PENGEMBANGAN SISTEM PENYEDIAAN AIR MINUM UNTUK IKK KECAMATAN MOJOTENGAH PDAM KABUPATEN WONOSOBO
}

\author{
Muhammad Fachri Sidiq ${ }^{1)}$, Triyono ${ }^{2)}$, Diananto Prihandoko ${ }^{3)}$ \\ 1223) Program Studi Teknik Lingkungan, Fakultas Teknik Lingkungan, Institut Teknologi Yogyakarta \\ email: muhamadfachrisidiq12@gmail.com 1); triyono@ity.ac.id ${ }^{2)}$; dito19@ity.ac.id ${ }^{3)}$
}

\begin{abstract}
ABSTRAK
Perusahaan Daerah Air Minum (PDAM) sebagai instansi pemerintah daerah yang bergerak di bidang penyediaan dan pelayanan air minum kepada masyarakat. Kabupaten Wonosobo memiliki 901.814 jiwa dan PDAM Kabupaten Wonosobo melayani 88.432 pelanggan serta pelanggan yang aktif sebesar 84.086 pelanggan dengan cakupan wilayah pelayanan $81,02 \%$. Dari latar belakang tersebut maka dilakukan penelitian di wilayah Kecamatan Mojotengan Kabupaten Wonosobo. Maka penelitian dilakukan untuk Pengembangan Sistem Penyediaan Air Minum Untuk Zona Pelayanan Kecamatan Mojotengah PDAM Kabupaten Wonosobo dengan menggunakan simulasi Epanet untuk proyeksi 20 tahun ke depan yang untuk saat ini melayani 4.817 SR dengan status pelanggan aktif, dan akan melakukan perencanaan di daerah Desa Andongsili sejumlah 801 SR. Dari penelitian tersebut diperoleh hasil data primer seperti tekanan air eksisting dan kondisi fisik lokasi perencanaan, dan data sekunder seperti jumlah penduduk lokasi pengembangan tahun 2020-2040 Debit Sumber Air DRD/DSML Daerah Eksisting Peta wilayah pengembangan Elevasi Panjang pipa. Berdasarkan hasil perencanaan pengembangan dapat dijadikan sebagai pertimbangan pelaksanaan pembuatan jaringan baru . Dengan kebutuhan air pada tahun 2040 di desa Andongsili sebesar 7,16 lt/dt. Dari hasil running Epanet 2.0 kebutuhan diameter untuk jaringan transmisi sebesar $100 \mathrm{~mm}$. Kapasitas reservoir pembagi untuk kebutuhan pelayanan di desa andongsili sebesar 198,8 m3. Jumlah penduduk berdasarkan hasil perhitungan proyeksi penduduk di desa Andongsili pada tahun 2040 sebesar 3.202 jiwa maka diperoleh 801 sambungan rumah dengan asumsi 4 jiwa/SR. Pada jaringan distribusi utama menggunakan pipa HDPE $100 \mathrm{~mm}$ sedangkan jaringan distribusi sekunder menggunakan pipa HDPE $50 \mathrm{~mm}$. Berdasarkan running epanet diperoleh tekanan tertinggi sebesar 91,09 mka di J6 dan tekanan terendah 19,71 mka di node N40.

Kata Kunci : Perencanaan, Simulasi Epanet 2.0, Pengembangan SPAM
\end{abstract}

\section{PLAN FOR THE DEVELOPMENT OF A DRINKING WATER SUPPLY SYSTEM FOR IKK MOJOTENGAH PDAM WONOSOBO DISTRICT}

\section{ABSTRACT}

Regional Drinking Water Company (PDAM) as the instasi of local government engaged in the provision and service of drinking water to the community. Wonosobo regency has 901,814 people and PDAM Wonosobo serves 88,432 customers and active customers of 84,086 customers with a service area coverage of $81.02 \%$. From this background, research was carried out in the district mojotengan Wonosobo regency. So the research was conducted for the Development of Drinking Water Supply System for Service Zone Mojotengah District PDAM Wonosobo regency by using epanet simulation for the projection of the next 20 years which for now serves 4817 $S R$ with active customer status, and will conduct planning in andongsili village area of 801 SR. From the research obtained the results of primary data such as existing water pressure and physical condition of the planning location, and secondary data such as The Number of Population Development Locations in 2020-2040 Discharge Water Source DRD / DSML Existing Area Map of the area of development of Long Elevation pipe. Based on the results of development planning can be used as a consideration for the implementation of the creation of a new network. With water needs in 2040 in Andongsili village of $7.16 \mathrm{lt} / \mathrm{s}$ from running epanet 2.0 needs diameter for transmission network of $100 \mathrm{~mm}$. The capacity of the dividing reservoir for service needs in andongsili village is 198.8 m3. The number of people based on the calculation of the projected population in Andongsili village in 2040 of 3,202 people was obtained 801 house connections assuming 4 people / SR. In the main distribution network using HDPE pipe $100 \mathrm{~mm}$ while secondary distribution network using HDPE pipe $50 \mathrm{~mm}$. Based on running epanet obtained the highest pressure of $91.09 \mathrm{mka}$ in J6 and the lowest pressure of $19.71 \mathrm{mka}$ on node N40. Keywords: Planning, Simulation Epanet 2.0 , SPAM Development

\section{PENDAHULUAN}

Air adalah sumber daya alam yang sangat di butuhkan bagi semua makhluk hidup. Dapat dikatakan pula air adalah sumber dari kehidupan kita. Seiring dengan berjalanya waktu banyak masalah yang muncul pada sistem penyediaan air bersih, diantaranya seperti limbah cair dari pabrik dan pertumbuhan perumahan yang pesat sehingga tidak dapat memanfaatkan air tanah/sumur. 
Perusahaan Daerah Air Minum (PDAM) sebagai instansi pemerintah daerah yang bergerak di bidang pelayanan air bersih. Dalam menyediakan dan pelayanan air minum kepada masyarakat sistem jaringan distribusi sangat penting maka fungsi dari jaringan pipa distribusi adalah untuk menghantarkan air bersih ke seluruh pelanggan atau masyarakat dengan memperhatikan kualita, kuantitas, dan kontinuitas

PDAM Kabupaten Wonosobo memiliki tanggung jawab sebagai perusahaan penyediaan dan pelayanan air bersih. Kabupaten Wonosobo memiliki 901.814 jiwa dan PDAM Kabupaten Wonosobo melayani 88.432 pelanggan serta pelanggan yang aktif sebesar 84.086 pelanggan dengan cakupan wilayah pelayanan $81,02 \%$ dari semua wilayah cakupan pelayanan. ( PDAM Kabupaten Wonosobo 2020)

Untuk mencapai cakupan pelayanan 100\% sesuai target yang diinginkan PDAM Kabupaten Wonosobo bertujuan untuk melakukan pengembangan pelayanan di tahun 2020 dengan Memanfaatkan sumber mata air Melikan dengan kapasitas 12,4 1/detik yang berada di kecamatan Mojotengah Kabupaten Wonosobo. Agar dapat memperoleh hasil yang baik dalam pengembangan jaringan perlu memanfaatkan teknologi komputerisasi yang dapat menggambarkan simulasi hidrolis yang mengalir di dalam pipa. PDAM Kabupaten Wonosobo akan membuat pengembangan jaringan distribusi baru untuk melayani sambungan rumah di Kecamatan Mojotengan Kabupaten Wonosobo.

\section{METODE PENELITIAN}

1. Identifikasi Masalah

Identifikasi masalah dilakukan untuk membatasi masalah yang dilakukan dalam penelitian. Permasalahan yang terdapat pada penelitian adalah PDAM Kabupaten Wonosobo memiliki mata air berkapasitas 12, $4 \mathrm{~L} / \mathrm{dt}$ yaitu mata air Melikan yang belum termanfaatkan.

2. Pengumpulan Data

Untuk mengetahui atas suatu rumusan masalah dan tujuan penelitian ini, maka perlu mengumpulkan data. Berikut adalah data yang diperlukan untuk pengambilan data melakukan perencanaan jaringan pada jaringan pipa distribusi:

Data Primer meliputi tekanan Eksisting dan Kondisi fisik lokasi Perencanaan sedangakan untuk data Sekunder meliputi Jumlah Penduduk Lokasi Pengembangan tahun 2020-2040, Debit Eksisting, DRD dan DSML daerah Eksisting, Peta wilayah pengembangan, Elevasi dan Panjang Pipa.

\section{HASIL DAN PEMBAHASAN}

\section{HASIL}

1. Skema SPAM di Unit Mojotengah

Deskripsi cakupan pelayanan Desa Kalibeber, Desa Andongsili, Desa Bumirejo, Desa Kebrengan, Desa Mojosari, Desa Keseneng, Desa Blederan, Desa Candirejo, Desa Deroduwur, dan Desa Derongisor secara umum dapat dijelaskan pada Gambar 1 sebagai berikut:

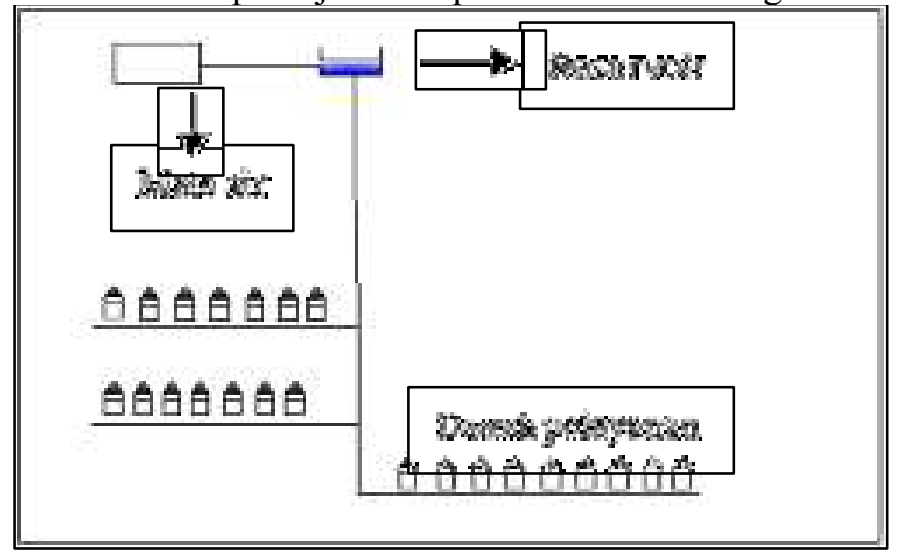

Gambar 1. Skema Jaringan Unit Mojotengah

Dari gambar diatas dapat diketahui skema SPAM di Unit Mojotengah mulai dari pengambilan sumber air dari mata air selanjutnya di tampung pada bangunan reservoir dan pendistribusian ke sambungan rumah dengan sistem gravitasi. 
2. Skema SDAM di Unit Mojotengah

Jaringan pipa distribusi Unit Mojotengah melayani 10 desa diantaranya dapat dilihat pada Tabel 1 sebagai berikut:

Tabel 1. Jumlah Penduduk Kecamatan Mojotengah

\begin{tabular}{cc}
\hline Desa & $\begin{array}{c}\text { Jumlah Penduduk } \\
\text { Pelayanan }\end{array}$ \\
\hline Kalibeber & 8.703 jiwa \\
Andongsili & 3.509 jiwa \\
Bumirejo & 4.210 jiwa \\
Kebrengan & 1.584 jiwa \\
Mojosari & 3.048 jiwa \\
Keseneng & 1.803 jiwa \\
Blederan & 2.803 jiwa \\
Candirejo & 1.365 jiwa \\
Deroduwur & 3.300 jiwa \\
Derongisor & 2.594 jiwa \\
\hline
\end{tabular}

Sumber : Data BPS

Skema SDAM di Unit Mojotengah dapat dilihat pada Gambar 2 sebagai berikut:

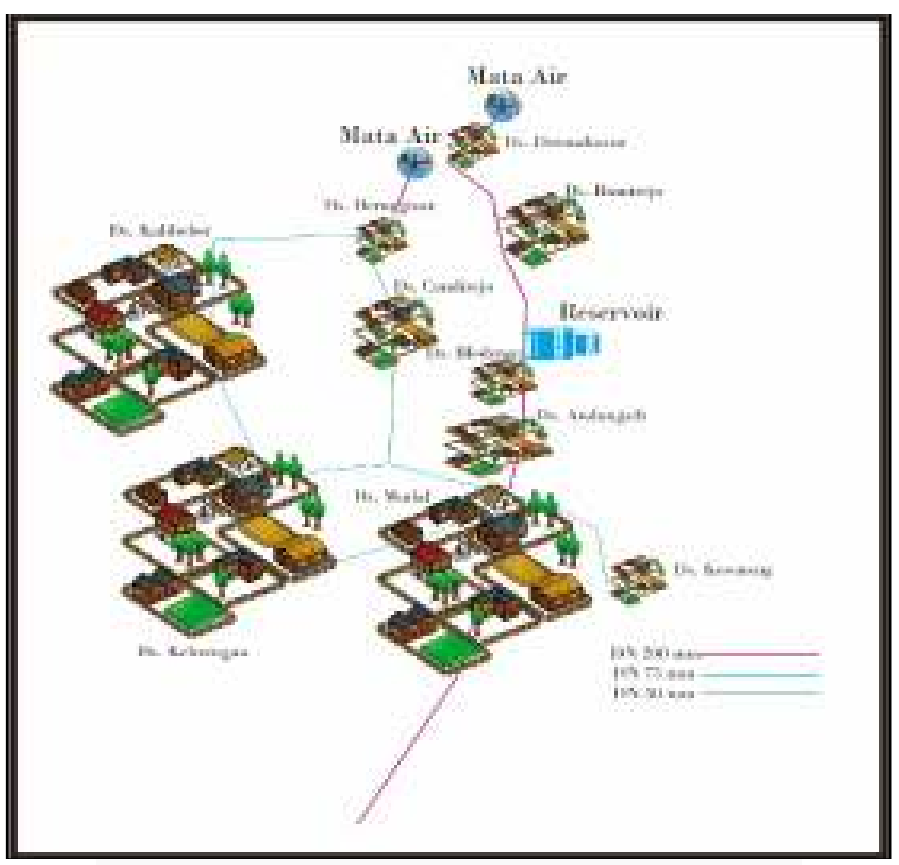

Gambar 2. Skema SDAM di Unit Mojotengah

Dari gambar diatas dapat dijelaskan peta jaringan pipa distribusi di Unit Mojotengah. Jumlah sambungan rumah yang dilayani Unit Mojotengah yaitu 4.817 SR. Untuk jumlah penduduk pelayanan dan jumlah sabungan rumah.

3. Kondisi Unit Air Baku

Sumber air yang dimanfaatkan pada sistem perpipaan Unit Mojotengah adalah Mata air Silanang, Mata air Siwadon, Mata air Mudal dengan total kapasitas terpasang sebesar 160 lt/dt. Sedangkan untuk daerah perencanaan di Desa Andongsili menggunakan Mata Air Melikan dengan kapasitas terpasang $12,4 \mathrm{lt} / \mathrm{dt}$ 
4. Kondisi Unit Transmisi dan Distribusi

Pada Unit Mojotengah sistem pengaliran menggunakan sistem gravitasi dari broncaptering kemudian sistem pendistribusian rata rata menggunakan reservoir dengan kapasitas $1.500 \mathrm{~m} 3$.

5. Kondisi Unit Pelayanan

Unit Mojotengah untuk saat ini melayani 4.817 SR dengan status pelanggan aktif, dan akan melakukan perencanaan di daerah Desa Andongsili sejumlah 801 SR.

6. Perencanaan pengembangan SPAM

Pola Pemakaian air Desa Blederan ( Esisting )

Data pola pemakaian air di setiap wilayah berbeda-beda yang dipengaruhi oleh beberapa faktor seperti kondisi wilayah, kondisi jaringan, sosial budaya, serta tingkat perekonomian masyarakat. Data pola pemakaian di Desa Blederan ( Esisiting) yang karakternya sama seperti desa andongsili sebagai desa untuk melakukan perencanaan. Data diperoleh dari pencatatan debit menggunakan Logger selama 24 jam yang bertujuan untuk mengetahui fluktuasi pemakaian air pelanggan di Desa Andongsili. Fluktuasi pemakaian air di Desa Andongsili dapat dilihat pada Tabel 2 sebagai berikut:

Tabel 2. Fluktuasi Pemakaian Air

\begin{tabular}{|c|c|c|c|c|c|}
\hline \multirow{2}{*}{ No } & \multirow{2}{*}{ Jam } & Debit & Debit & \multirow{2}{*}{$\begin{array}{l}\text { Debit } \\
\text { Rata- } \\
\text { Rata }\end{array}$} & \multirow{2}{*}{$\begin{array}{l}\text { Flow } \\
\text { Factor }\end{array}$} \\
\hline & & (m3/h) & (1/detik) & & \\
\hline 1 & 00.00 & 1,2 & 0,3 & 3,72 & 0,09 \\
\hline 2 & 01.00 & 1 & 0,3 & 3,72 & 0,07 \\
\hline 3 & 02.00 & 1,8 & 0,5 & 3,72 & 0,13 \\
\hline 4 & 03.00 & 2,9 & 0,8 & 3,72 & 0,22 \\
\hline 5 & 04.00 & 6,5 & 1,8 & 3,72 & 0,49 \\
\hline 6 & 05.00 & 9,5 & 2,6 & 3,72 & 0,71 \\
\hline 7 & 06.00 & 10 & 2,8 & 3,72 & 0,75 \\
\hline 8 & 07.00 & 8 & 2,2 & 3,72 & 0,60 \\
\hline 9 & 08.00 & 12,2 & 3,4 & 3,72 & 0,91 \\
\hline 10 & 09.00 & 10 & 2,8 & 3,72 & 0,75 \\
\hline 11 & 10.00 & 9,5 & 2,6 & 3,72 & 0,71 \\
\hline 12 & 11.00 & 10 & 2,8 & 3,72 & 0,75 \\
\hline 13 & 12.00 & 10 & 2,8 & 3,72 & 0,75 \\
\hline 14 & 13.00 & 6,5 & 1,8 & 3,72 & 0,49 \\
\hline 15 & 14.00 & 5 & 1,4 & 3,72 & 0,37 \\
\hline 16 & 15.00 & 8 & 2,2 & 3,72 & 0,60 \\
\hline 17 & 16.00 & 11 & 3,1 & 3,72 & 0,82 \\
\hline 18 & 17.00 & 14 & 3,9 & 3,72 & 1,05 \\
\hline 19 & 18.00 & 11 & 3,1 & 3,72 & 0,82 \\
\hline 20 & 19.00 & 6,5 & 1,8 & 3,72 & 0,49 \\
\hline 21 & 20.00 & 4 & 1,1 & 3,72 & 0,30 \\
\hline 22 & 21.00 & 4 & 1,1 & 3,72 & 0,30 \\
\hline 23 & 22.00 & 1,8 & 0,5 & 3,72 & 0,13 \\
\hline 24 & 23.00 & 2,8 & 0,8 & 3,72 & 0,21 \\
\hline & nlah & 167,2 & 46,4 & & 12,50 \\
\hline & ta-Rata & 6,97 & 3,72 & & 0,52 \\
\hline
\end{tabular}

Sumber : Data Loger 
Tabel 3. Data Rekening Ditagih

\begin{tabular}{ccccc}
\hline \multirow{2}{*}{ No. } & \multirow{2}{*}{ Bulan } & Jumlah & Debit & Debit \\
\cline { 3 - 5 } & & SR & $\mathrm{m}^{3} /$ bulan $/ \mathrm{sr}$ & $\mathrm{L} / \mathrm{Sr} / \mathrm{hr}$ \\
\hline 1. & Mei & 1934 & 16,190 & 539,69 \\
2. & Juni & 1934 & 17,254 & 575,16 \\
3. & Juli & 1905 & 14,472 & 482,41 \\
\multicolumn{2}{c}{ Rata-Rata } & 15,972 & 532,42 \\
\hline
\end{tabular}

Suber : PDAM Kabupaten Wonosobo

Dari tabel diatas data rekening ditagih selama 3 bulan digunakan untuk mencari Kebutuhan air pada pelayanan unit Mojotengah.

7. Proyeksi Kebutuhan Air

Perencanaan jaringan sistem distribusi air minum juga memperhatikan pertumbuhan jumlah penduduk di suatu daerah dalam kurun waktu tertentu. Hal ini sangat bermanfaat guna memprediksi jumlah kebutuhan air pada massa yang akan datang serta kemampuan daya tampung pipa pada massa yang akan datang pula. Dalam hal ini perhitungan proyeksi penduduk untuk wilayah perencanaan desa Andongsili menggunakan metode Eksponential karena dalam perhitungan ini dinilai lebih effisien dari segi perhitungan dan tingkat nilai korelasinya yang mendekati 1 . Hasil rekapitulasi Proyeksi Penduduk dapat dilahat pada Tabel 4 sebagai berikut.

Metode Exponensial

Rumus:

$$
P n=a \cdot e^{b \cdot x}
$$

\section{Keterangan :}

Pn = Jumlah Penduduk tahun ke $-\mathrm{n}$

$\mathrm{e} \quad=$ Bilangan exponensial

$\mathrm{x} \quad=$ Proyeksi penduduk

$\mathrm{n} \quad=$ Jumlah data penduduk

$\mathrm{n} \quad=$ Jumlah data penduduk

$$
\begin{gathered}
\ln a=\left[\sum(\ln y)-b \cdot \sum x\right] / n \\
b=\frac{\left.\sum \quad x \cdot \ln \ln y\right)-\left(\sum x \cdot \sum \ln y / n\right)}{\sum x^{2}-\left(\left(\sum x\right)^{2} / n\right)} \\
r^{2}=\frac{\left(\ln a \cdot \sum \ln y+b \cdot \sum(x \cdot \ln \ln y)-\left(\sum \quad n y\right)^{\wedge} n\right.}{\left(\sum \quad \ln y^{\wedge} 2\right)-\left(\left(\sum \ln y\right)^{2} / n\right)}
\end{gathered}
$$


Tabel 4. Hasil Rekapitulasi Proyeksi Penduduk

\begin{tabular}{cccc}
\hline TAHUN & LOGARITHMIC & EXPONENTIAL & LEAST SQUARE \\
\hline 2020 & 3.063 & 3.069 & 3.069 \\
2021 & 3.066 & 3.076 & 3.076 \\
2022 & 3.067 & 3.082 & 3.082 \\
2023 & 3.069 & 3.089 & 3.089 \\
2024 & 3.070 & 3.095 & 3.095 \\
2025 & 3.071 & 3.102 & 3.102 \\
2026 & 3.072 & 3.108 & 3.108 \\
2027 & 3.073 & 3.115 & 3.115 \\
2028 & 3.074 & 3.122 & 3.121 \\
2029 & 3.075 & 3.128 & 3.128 \\
2030 & 3.075 & 3.135 & 3.134 \\
2031 & 3.076 & 3.142 & 3.141 \\
2032 & 3.077 & 3.148 & 3.147 \\
2033 & 3.077 & 3.155 & 3.154 \\
2034 & 3.078 & 3.162 & 3.160 \\
2035 & 3.078 & 3.168 & 3.167 \\
2036 & 3.079 & 3.175 & 3.173 \\
2037 & 3.079 & 3.182 & 3.180 \\
2038 & 3.080 & 3.189 & 3.186 \\
2039 & 3.080 & 3.195 & 3.193 \\
2040 & 3.080 & 3.202 & 3.199 \\
Korelasi & 0,5185 & 1,0000 & 0,4102 \\
\hline Sw & & &
\end{tabular}

Sumber : Pengolahan Data Penulis

8. Analisis Unit Air Baku

Sumber air yang digunakan untuk daerah perencanaan di desa Andongsili Kecamatan Mojotenggah Kabupaten Wonosobo menggunakan mata air Melikan \pm 1196 MDPL di titik koordinat Longtitude $109,936995^{\circ}$ Latitude $-7,273653^{\circ}$ Dengan kapasitas produksi 12,4 1/dt.

Berikut adalah hasil dari kalitas mata air Melikan :

Tabel 5. Hasil Kualitas Mata Air Melikan

\begin{tabular}{llccc}
\hline \multirow{2}{*}{ No } & \multicolumn{1}{c}{ Parameter } & Satuan & $\begin{array}{c}\text { Permenkes No 492 tahun } \\
2010\end{array}$ & Hasil Penelitian \\
\hline A & Fisika & & Suhu udara \pm 3 & 28 \\
1 & Suhu & ${ }^{\circ} \mathrm{C}$ & 15 & 2,7 \\
2 & Warna & $\mathrm{TCU}$ & 5 & $<1$ \\
3 & Kekeruhan & $\mathrm{NTU}$ & 500 & 71,8 \\
4 & Zat Padat Terlarut ( TDS) & $\mathrm{mg} / \mathrm{L}$ & & \\
$\mathrm{B}$ & Kimia & & $6,5-8,5$ & 7,5 \\
1 & Ph & $\mathrm{mg} / \mathrm{L}$ & 0,3 & 0,01 \\
2 & Besi (Fe) & $\mathrm{mg} / \mathrm{L}$ & 0,4 & 0,02 \\
3 & Mangan (Mn) & $\mathrm{mg} / \mathrm{L}$ & 500 & 64,97 \\
4 & Kesadahan (CaCO 3) & & \\
\hline
\end{tabular}

Sumber : Hasil dari Laboratorium kesehatan Banjarnegara Ceria

Berdasarkan Tabel 5. menunjukan bahwa parameter yang diambil fisik dan kimia sesuai dengan hasil labratorium bahwa parameter Suhu 28, Warna 2,7, Kekeruhan $<1$, TDS 71,8, Ph 7,5 , Besi (Fe) 0,01, Mangan (Mn) 0,02, dan Kesadahan 64,97 dari hasil tersebut kualitas air pada Mata air Melikan layak sebagai air yang bisa diminum atau di konsumsi karena sesuai dengan kriteria 
kualitas air minum yaitu Permenkes No 492 tahun 2010.

9. Perencanaan Reservoir

Reservoir distribusi ini difungsikan untuk menampung air disaat pemakaian lebih sedikit dari suplai dan untuk menutupi kekurangan air disaat pemakaian lebih besar dari suplai air. Air yang disuplai tersebut harus mencukupi kebutuhan masyarakat dalam sehari disamping itu juga reservoir distribusi di desa Anadongsili dipergunakan untuk melepaskan tekanan. Oleh karena itu dibutuhkan reservoir yang dapat menampung air untuk mencukupi kebutuhan selama pompa mati. Pemilihan lokasi reservoir berada di elevasi paling tinggi dari daerah pelayanan yaitu $1073 \mathrm{mdpl}$.

Tabel 6. Rekapitulasi rencana Pembangunan Reservoir

\begin{tabular}{clcc}
\hline No & \multicolumn{1}{c}{ Uraian } & Satuan & $\begin{array}{c}\text { Hitungan } \\
\text { Perencanaan }\end{array}$ \\
\hline 1 & Debit & L/detik & 9,76 \\
2 & Dimensi Reservoir & $\mathrm{m}^{3}$ & 198,8 \\
3 & Panjang reservoir & $\mathrm{m}$ & 7 \\
4 & Lebar reservoir & $\mathrm{m}$ & 4 \\
5 & Tinggi reservoir & $\mathrm{m}$ & 7,1 \\
\hline
\end{tabular}

Sumber : Hasil Perhitungan Penulis

10.Hasil Simulasi Epanet 2.0

1. Hasil Running Epanet 2.0

Pengolahan data menggunakan Epanet 2.0, Simulasi dilakukan untuk mengetahui hidrolika perpipaan pada daerah perencanaan. Berikut adalah hasil simulasi pada saat jam puncak dapat dilihat pada Gambar 3,4,5,6 sebagai berikut.

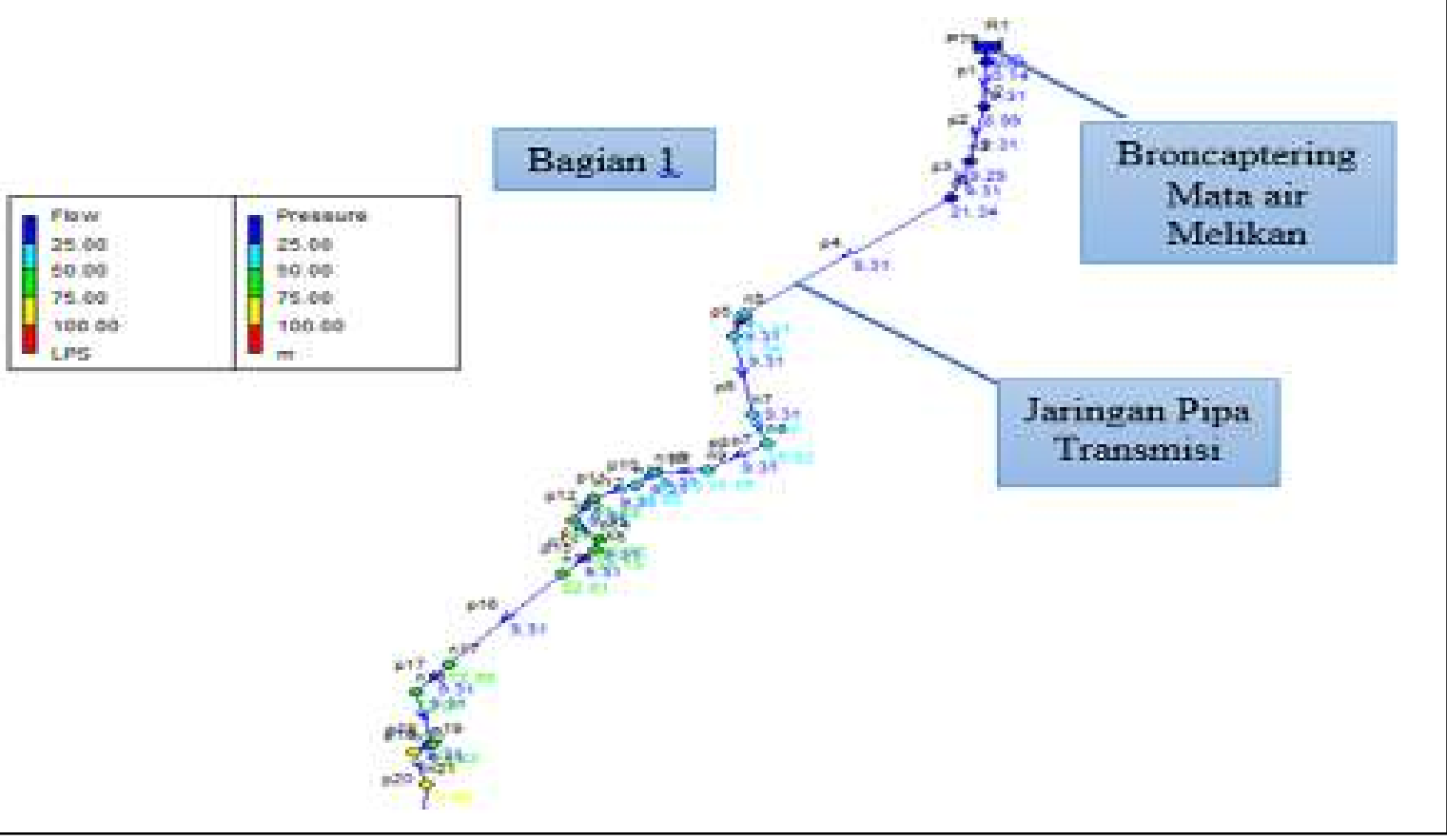

Gambar 3. Running Epanet 2.0 Saat Jam Puncak (Bagian 1) 


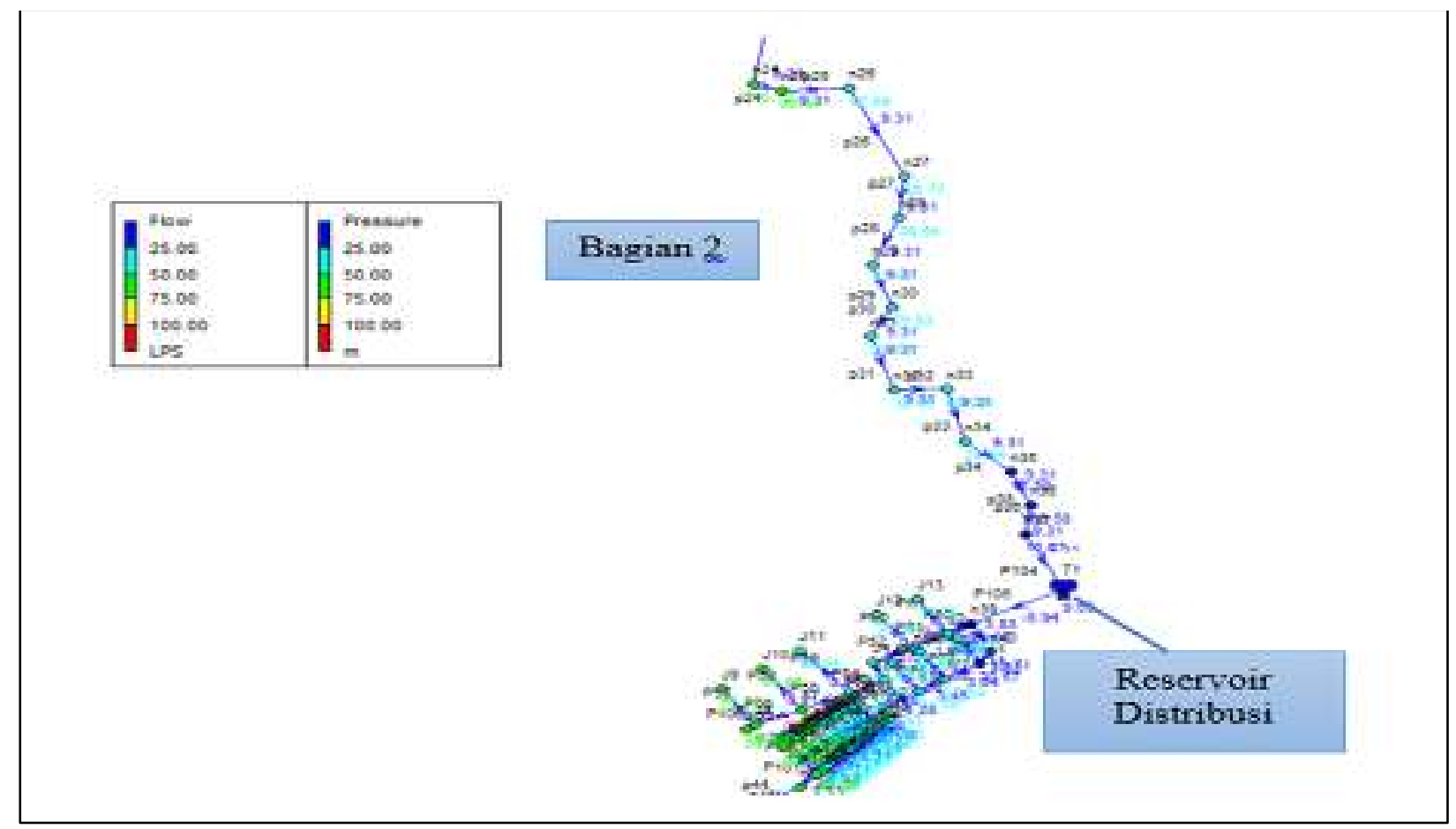

Gambar 4. Running Epanet 2.0 Saat Jam Puncak (Bagian 2)

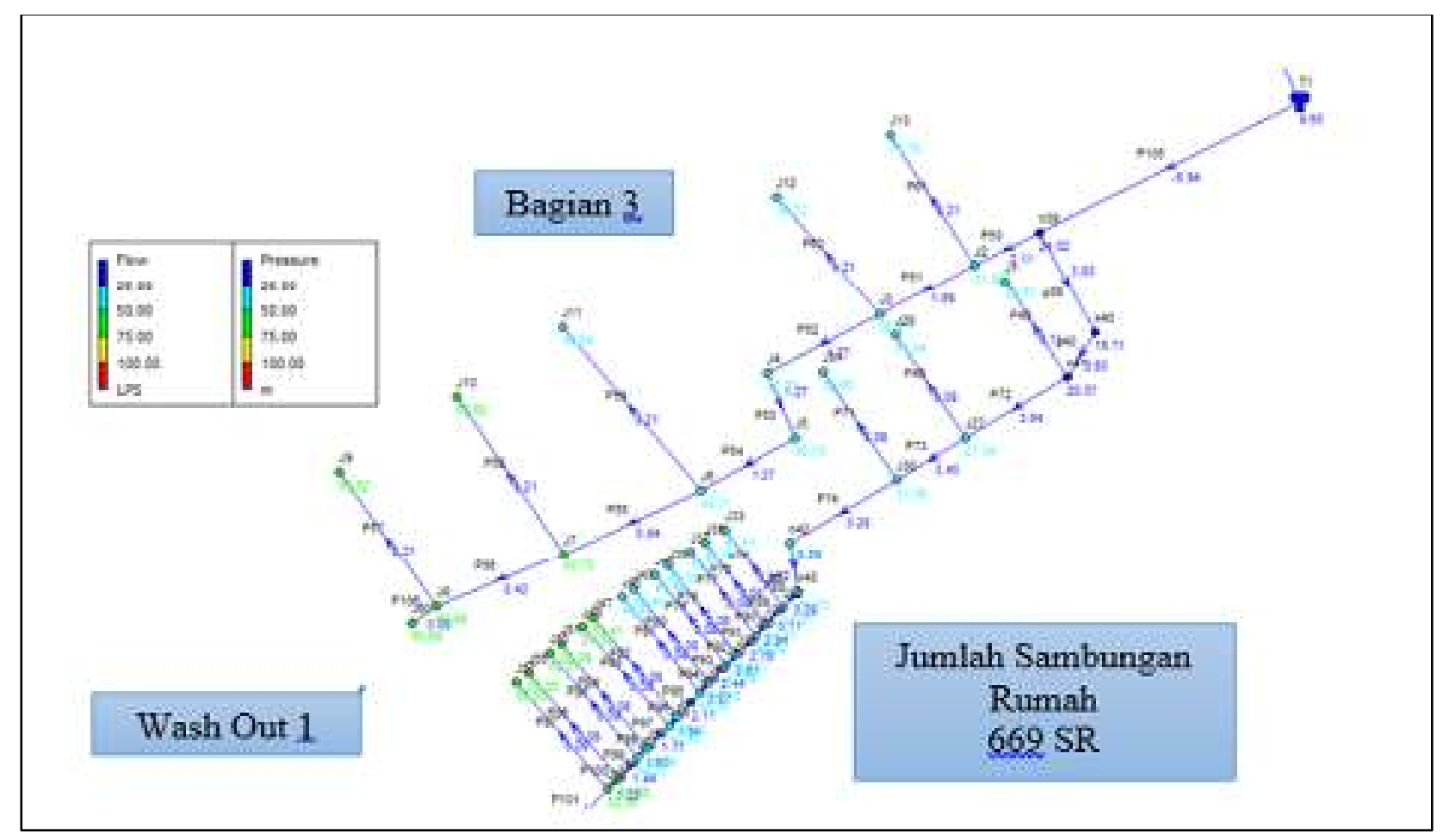

Gambar 5. Running Epanet 2.0 Saat Jam Puncak (Bagian 3) 


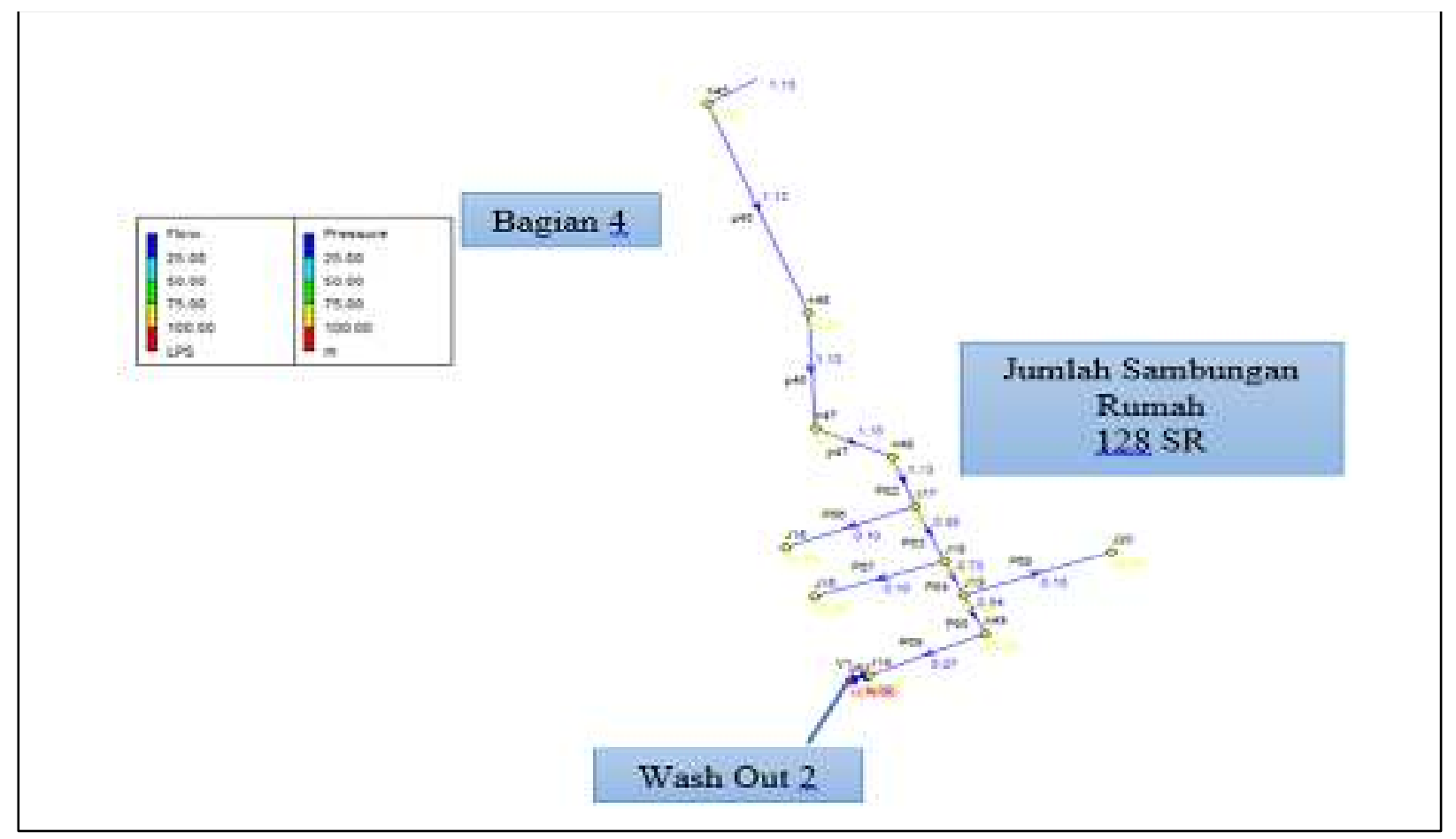

Gambar 6. Running Epanet 2.0 Saat Jam Puncak (Bagian 4)

2. Hasil Tekanan pada Jam Puncak di Setiap Node berikut.

Berikut adalah hasil running tekanan di Epanet yang terdapat pada Gambar 7 sebagai

Tabel 7. Hasil Tekanan Pada Jam Puncak

\begin{tabular}{cccc}
\hline \multirow{2}{*}{ Node ID } & Presure & \multirow{2}{*}{ Node ID } & Presure \\
& MKA & & MKA \\
\hline node 1 & 0.14 & Junc J5 & 39.75 \\
node 2 & 8.99 & Junc J6 & 44.71 \\
node 3 & 9.29 & Junc J7 & 50.70 \\
node 4 & 21.34 & Junc J8 & 60.69 \\
node 5 & 31.34 & Junc J9 & 63.62 \\
node 6 & 31.26 & Junc J10 & 53.63 \\
node 7 & 27.32 & Junc J11 & 48.64 \\
node 8 & 26.82 & Junc J12 & 39.72 \\
node 9 & 34.46 & Junc J13 & 34.78 \\
node 10 & 43.75 & Junc J14 & 90.00 \\
node 11 & 48.83 & Junc J15 & 91.08 \\
node 12 & 55.28 & Junc J16 & 91.09 \\
node 13 & 58.00 & Junc J17 & 86.10 \\
node 14 & 50.72 & Junc J18 & 86.09 \\
node 15 & 54.13 & Junc J19 & 85.09 \\
node 16 & 52.51 & Junc J20 & 82.08 \\
node 17 & 72.65 & Junc J1 & 26.57 \\
node 18 & 72.97 & Junc J27 & 27.34 \\
node 19 & 74.33 & Junc J28 & 31.34 \\
node 20 & 77.56 & Junc J30 & 31.06 \\
\hline
\end{tabular}

73 |Perencanaan Pengembangan Sistem Penyediaan Air Minum untuk IKK Kecamatan Mojotengah PDAM Kabupaten Wonosobo 


\begin{tabular}{|c|c|c|c|}
\hline node 21 & 75.89 & Junc J31 & 35.06 \\
\hline node 22 & 64.33 & Junc J32 & 37.61 \\
\hline node 23 & 63.17 & Junc J33 & 41.61 \\
\hline node 24 & 70.72 & Junc J34 & 39.57 \\
\hline node 25 & 65.57 & Junc J35 & 43.57 \\
\hline node 26 & 42.89 & Junc J36 & 40.54 \\
\hline node 27 & 36.77 & Junc J37 & 43.53 \\
\hline node 28 & 38.65 & Junc J38 & 42.51 \\
\hline node 29 & 42.91 & Junc J39 & 45.50 \\
\hline node 30 & 39.50 & Junc J40 & 42.48 \\
\hline node 31 & 38.76 & Junc J41 & 46.48 \\
\hline node 32 & 38.85 & Junc J42 & 44.45 \\
\hline node 33 & 25.76 & Junc J43 & 48.45 \\
\hline node 34 & 25.94 & Junc J44 & 45.43 \\
\hline node 35 & 16.52 & Junc J45 & 49.43 \\
\hline node 36 & 16.58 & Junc J46 & 46.41 \\
\hline node 37 & 16.07 & Junc J47 & 51.41 \\
\hline node 39 & 24.02 & Junc J48 & 47.40 \\
\hline node 40 & 19.71 & Junc J49 & 51.39 \\
\hline node 41 & 20.57 & Junc J50 & 49.38 \\
\hline node 42 & 35.83 & Junc J51 & 53.38 \\
\hline node 43 & 33.73 & Junc J52 & 49.37 \\
\hline node 44 & 59.34 & Junc J53 & 53.37 \\
\hline node 45 & 76.30 & Junc J54 & 51.36 \\
\hline node 46 & 88.20 & Junc J55 & 55.36 \\
\hline node 47 & 83.16 & Junc J56 & 52.36 \\
\hline node 48 & 81.13 & Junc J57 & 56.35 \\
\hline node 49 & 84.08 & Junc J60 & 60.69 \\
\hline Junc J2 & 31.88 & Junc J61 & 90.00 \\
\hline Junc J3 & 36.81 & Resvr R1 & 0.00 \\
\hline Junc J4 & 40.77 & Tank T1 & 9.65 \\
\hline
\end{tabular}

Sumber : Pengolahan data Penulis

Dari hasil running pada epanet jaringan distribusi Desa Andongsili pada tahun perencanaan 2040 pada jam puncak diatas bahwa dapat disimpulkan bahwa tekanan tertinggi adalah 91,09 pada juction 6 , sedangkan tekanan terendah adalah 19,71 pada node 40. Berikut rekapitulasi data tekanan tertinggi hingga terendah pada Tabel 8.

Tabel 8. Hasil Rekapitulasi Tekanan dari yang Tertinggi hingga Terendah

\begin{tabular}{cccc}
\hline \multicolumn{4}{c}{ Rekap data tekanan tahun perencanaan 2040 } \\
\hline No.Node & $\begin{array}{c}\text { Presure } \\
\text { (Mka) }\end{array}$ & $\begin{array}{c}\text { Elevasi } \\
\text { (Mdpl) }\end{array}$ & Keterangan \\
\hline J6 & 91,09 & 988 & \\
J15 & 91,08 & 988 & Tertinggi \\
J14 & 90,00 & 989 & \\
N40 & 19,71 & 1061 & \\
N41 & 20,57 & 1060 & Terendah \\
N39 & 24,02 & 1057 & \\
\hline
\end{tabular}

Sumber : Pengolahan Data Penulis 
Berikut adalah Profil Hidrolis Pipa pada gambar 7.

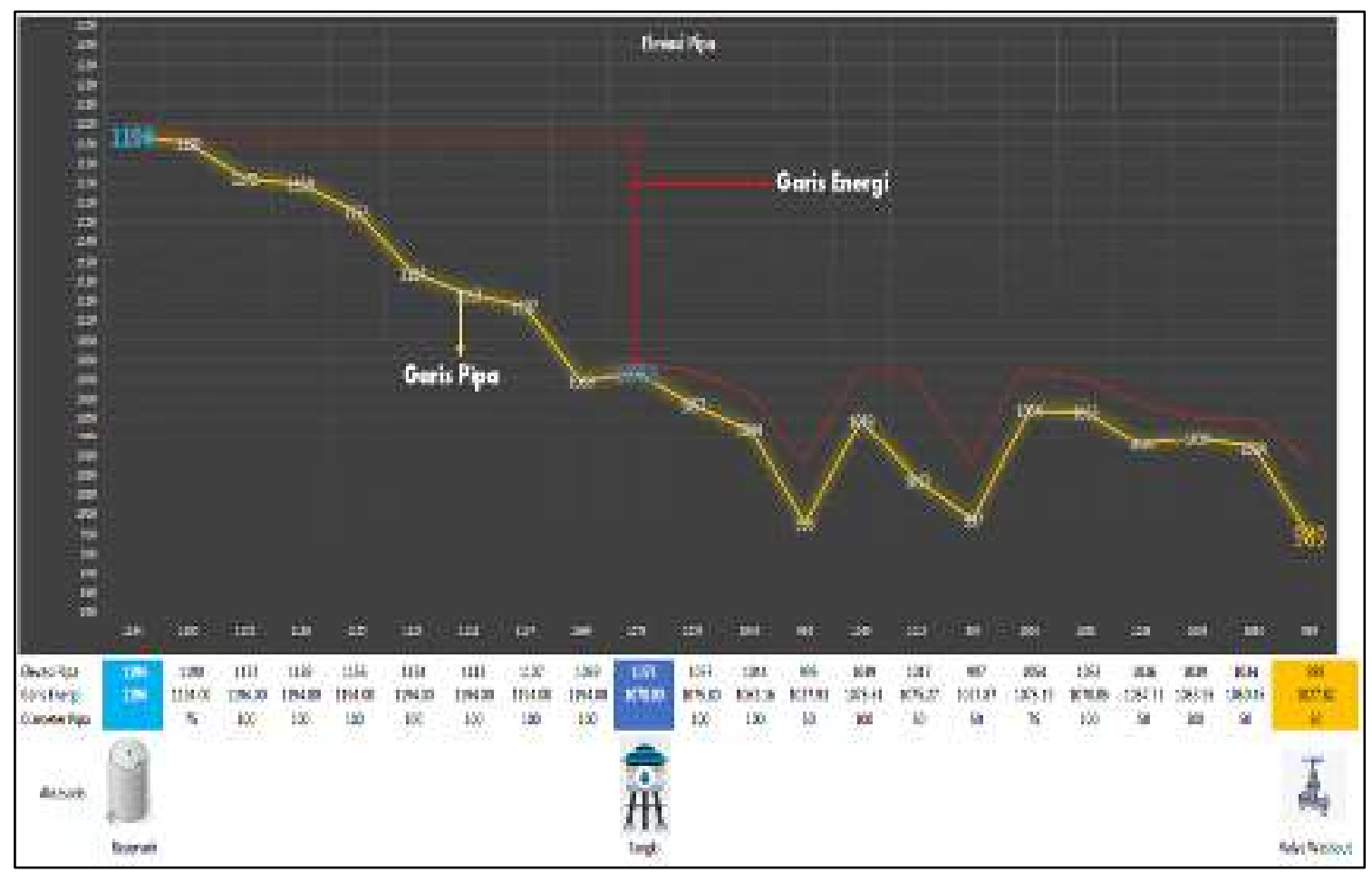

Gambar 7. Profil Hidrolis Pipa Desa Andongsili

\section{PEMBAHASAN}

1. Rencana Jaringan Transmisi

Letak mata air Melikan di desa Kreo Kejajar dengan kapasitas produksi 12,4 berada di ketinggian $\pm 1190 \mathrm{Mdpl}$, sedangkan rencana reservoir pembagi berada di ketinggian \pm 1073 Mdpl.dengan kondisi topopgrafi wilayah tersebut maka adanya reservoir pembagi juga dimanfaatkan sebagai pelepas tekanan karena perbedaan head yang cukup tinggi.

Dengan kebutuhan air pada tahun 2040 di desa Andongsili sebesar 7,16 lt/dt.dari hasil running epanet 2.0 kebutuhan diameter untuk jaringan transmisi sebesar $100 \mathrm{~mm}$.

2. Rencana Reservoir Distribusi

Kapasitas reservoir pembagi untuk kebutuhan pelayanan di desa andongsili sebesar 198,8 m3. Dengan adanya reservoir distribusi diharapkan suplai air pada jam puncak dan pada aliran malam minimum dapat terpenuhi sehingga terciptanya pengaliran air secara kontinuitas. Serta dengan adanya reservoir distribusi dapat mengurangi tekanan yang cukup tinggi di daerah pelayanan.

3. Rencana Jaringan Distribusi

Jumlah penduduk bedasarkan hasil perhitungan proyeksi penduduk di desa Andongsili pada tahun 2040 sebesar 3.202 jiwa maka diperoleh 801 sambungan rumah dengan asumsi 4 jiwa/SR.

Pada jaringan distribusi utama menggunakan pipa HDPE $100 \mathrm{~mm}$ diharapkan dengan adanya pengembangan pelanggan baru masih dapat memenuhi kriteria standar tekanan.sedangkan jaringan distribusi sekunder menggunakan pipa HDPE $50 \mathrm{~mm}$. berdasarkan running epanet diperoleh tekanan tertinggi sebesar 91,09 mka di J6 dan tekanan terendah 19,71 mka di node N40 Melihat perbedaan elevasi yang cukup tinggi tekanan masih tergolong aman untuk jaringan distribusi.

\section{KESIMPULAN}

Berdasarkan analisa perhitungan dalam perencanaan jaringan air bersih PDAM Kabupaten Wonosobo, dapat disimpulkan sebagai berikut : 
1. Kebutuhan air total untuk daerah pelayanan di Desa Andongsili Kecamatan Mojotengah pada tahun perencanaan 2040 kebutuhan air sebesar 618,624 1/hari atau 7,16 1/dt dengan $100 \%$ pelayanan dari jumlah penduduk 3202 jiwa atau 801 sambungan rumah (SR). Sehingga dengan kapasitas produksi dimata air melikan yang mencapai $12,41 / \mathrm{dt}$, Maka pada perencanaan desa andongsili dengan proyeksi jangka waktu 20 tahun debit air masih memenuhi.

2. Sistem jaringan distribusi menggunakan system bercabang (branch ). Hal ini dikarenkan letak topografi daerah perencanaan dalam jangkauan cukup jauh, serta elevasi yang cenderung seperti lembah. Sehingga sistem bercabang digunakan untuk mempermudah pengembangan jaringan baru. Jaringan perpipaan mengikuti bentuk jalan yang ada serta menggunakan simulasi epanet 2.0. jaringan distribusi membutuhkan pipa PVC dengan diameter $100 \mathrm{~mm}$ dan $50 \mathrm{~mm}$, serta aksesoris dan viting.

3. Rencana sistem jaringan distribusi pada tahun 2020-2040 pipa transmisi dan pipa JDU menggunakan pipa HDPE diameter $100 \mathrm{~mm}$ sedangkan untuk jaringan sekunder menggunakan pipa HDPE diameter $50 \mathrm{~mm}$ dengan tekanan tertinggi pada jaringan transmisi sebesar 144 mka di node 24 hal ini masih terggolong aman karena berdasarkan peraturan Permen PU No 18 tahun 2007 pada pipa HDPE $100 \mathrm{~mm}$ maksimal tekanan adalah 12,4 mpa.

\section{DAFTAR PUSTAKA}

Arya Rezagama, M. (2016). Jaringan Perpipaan Air Minum. yogyakarta: TEKNOSAIN.

Badan Pengembangan Sumber Daya Manusia. (2018). Modul Penyusunan DED dan RAB. Bandung: Kementerian Pekerjaan Umum dan Perumahan Rakyat.

Dharmasetiawan, M. (2004). Sistem Perpipaan Distribusi Air Minum. Jakarta: Ekamitra Engineering.

Dirjen Cipta Karya. (1996). Kriteria Perencanaan.

Dr.Ir. Bambang Triadmojo, C. (1993). Hidrolika 1. 38.

Joko, T. (2010). Unit Air Baku dalam Sistem Penyediaan Air Minum. Yogyakarta: Graha Ilmu.

PerMen PU No 18. (2007). Penyelenggaraan Pengembangan Sisitem Penyediaan Air Minum. Peraturan Mentri Pekerjaan Umum, 135.

Rossman, L. (2004). Epanet 2.0 User Manual. Jakarta: Ekamitra Engineering.

Rossman, L. A. (2000). Epanet 2.0 User Manual. Jakarta: Ekamitra Engineering.

Triatmodjo, B. (2009). Hidraulika II. Yogyakarta: Beta Offset. 